\title{
Optimal local pressure control in water distribution network based on
}

\author{
valve location \\ Chengui Chang1,a Xinyu Zhang1,b \\ ${ }^{1,2}$ School of Civil Engineering and Architecture, University of Jinan Jinan china \\ a chglll1979@139.com bcea_zhangxy@ujn.edu.cn
}

Keywords: water distribution network, DMA, sensitivity, pressure control, valve

Abstract. When accident or maintenance occurs in water distribution network, how to improve the service level of the user is the problem that urban water supply enterprises need to solve. This paper presents a optimization model based on DMA partitions for attempting to use the sensitivity method to find the pipelines which have greater impact on the partial pressure. Through the valves on the pipelines in water distribution network boundaries are regulated, the partial node pressure can be adjusted to adapt to the service requirements. An example of application shows that this method can basically realize the pressure regulation of the local water distribution network, to increase the service pressure of the water distribution network in the accident or maintenance.

\section{Introduction}

Water distribution network(WDN) is divided into smaller metered zones, which is the basis of optimal scheduling of WSN. Recent research on partition is focused on water district metering (DMA) or pressure zones (PMA) [1,2]. DMAs are created by dividing the water distribution network into several relatively independent zones by closing the valves on the pipelines on boundaries, and flow meters in the inlet and outlet pipes of each zone are installed, to monitor the flow in and out of each zone., which can improve the management efficiency of leakage in water distribution network. PMA are created by pressure of water distribution network. According to the closeness of the node pressure of nodes of water distribution network, the water distribution network is composed into several metered zones to be easily detected and managed. These pressure zones are then monitored for leakage and pressure control. An effective pressure management to reduce background leakage can then be implemented on these zones [5]. The main purpose of this management is to reduce difference rate between water production and sale, which mainly is caused by leakage of WDN. The metered zones by DMA (District Metering Area) or PMA (Pressure Metering Area) is done.

Usually between zones, valves are provided on the contact pipeline, which are usually out of the closed state. When accident in a zone or maintenance or overhaul in WDN occurs, to achieve water pressure and flow requirements of users, some valves between the various metered zones need be opened to ensure the service level of water distribution network. The number of valves on the metered zones boundaries is large. The deployment of these valves is mainly based on manual experience and site commissioning, which is time-consuming and laborious. This paper attempts to use some methods to speed up the operation time, and reduce the manual operation to improve the accuracy of valves regulation 


\section{Problem Formulation}

This study carries out the pressure control. based on the DMA, and the main purpose is to balance the pressure in the zones of water distribution network. The objective equation of optimization is the minimum of the sum of the rest node pressure of water distribution network in one day which supplied water pressure minus service water pressure, as follows :

$$
\min F(H, n)=\frac{\sum_{i=1}^{k} \sum_{j=1}^{n}\left(H_{i j}-H_{e}\right)^{2}}{n}
$$

Where $i$ is the period number, $j$ is the pipeline number, $H_{i j}$ is the $j$ node pressure in period $i, H_{c}$ is the minimum service pressure of WDN, $n$ is the number of nodes, and $k$ is the number of periods. The above minimization is subject to the following constraints:

- Energy conservation of WDN and node flow continuity equation

$$
F(Q, H)=0
$$

The network governs equations: These are the set of equations that describe the flow of water in the water distribution network.

Where are

$$
F(Q)=A q+Q=0
$$

$$
L h=0
$$

Where: $\boldsymbol{A}$ is cohesion matrix, $\boldsymbol{L}$ is loop matrix, $\boldsymbol{Q}$ is nodal flow vector, $\boldsymbol{h}$ is Pipeline pressure drop column vector

- Node pressure is greater than the minimum service pressure

$$
H_{i j} \geq H_{e}
$$

By the knowledge-based with GA, the boundary of DMAs is established [5]. Based on DMAs partition, the network will be divided into different zones by similar nodes which have closer change of node pressure

Under the premise of ensuring sufficient water pressure for the users, the water pressure should be equalized to reduce the leakage loss, energy consumption and the accident rate with partition in water distribution network. The following factors should be considered in the zone: the pressure distribution, the effect of pressure changes with the node pressure, the elevation of the terrain, the position of the inflow point, the shape of the zone and the situation of industrial water use.

\section{optimization-valve regulation sequence}

Main design parameters of the water supply pipe are variable, such as flow, flow rate, head loss, friction coefficient and other parameters, but in the process of scheduling, the friction coefficient in the network does not change in a day or a short period of time. Sensitivity analysis is introduced in the adjustment of the water distribution network based on valve, in order to solve the optimal adjustment sequence of the valves [7]. The law of conservation of energy and the continuity of nodes 
in a pipe network can be expressed as follows: The model of water distribution network is the dynamic hydraulic characteristics, which depends on the basic elements of the network to analyze the water distribution network with continuity equations and energy balance equations, which describes the network components and their interactions, boundary conditions etc. By solving the equations, water distribution network state is obtained.

Where are

$$
\begin{aligned}
& F(q, Q)=\sum \pm q_{i j}+Q_{i}=0 \\
& \operatorname{sgn}\left(H_{i}-H_{j}\right)\left(H_{i}-H_{j}\right)=S_{i j} Q_{i j}^{\alpha}
\end{aligned}
$$

Where: $\boldsymbol{Q}_{\boldsymbol{i}}$ is nodal flow, $\boldsymbol{Q}_{i j}$ is pipeline flow, $\boldsymbol{S}_{i j}$ is pipe friction coefficient

By (7) into (6), achieved:

$$
\sum_{\substack{i \neq j \\ j=1}}^{n} \frac{\partial F_{i}}{\partial H_{i}} \frac{\partial H_{i}}{\partial S_{m}}+\frac{\partial F_{i}}{\partial H_{j}} \frac{\partial H_{j}}{\partial S_{m}}=-\frac{\partial F_{i}}{\partial S_{m}}
$$

The differential sensitivity coefficient $\boldsymbol{K}$ of the friction coefficient $\boldsymbol{S}$ of each pipe under certain working conditions can be obtained:

$$
K_{i}=\frac{\partial H_{i}}{\partial S_{m}}
$$

Where: $H$ is head loss given by Hazan-Wiliiams

$$
H=\frac{10.67 q^{1.858}}{C_{w}{ }^{1.852} D^{4.87}} L
$$

Where: $C_{w}$ is the Hazen-Williams friction factor and $D$ is the pipe diameter (in $\mathrm{m}$ ), and $\mathrm{L}$ is pipe length.

The pipes which have great impact on the region is determined by the sensitivity coefficient of the friction coefficient. The more sensitive the friction coefficient sensitivity coefficient is, the better the adjustability of the pipe is. By adjusting the valves on the pipes which are sensitivity, the flow and pressure in zones of the water distribution network can be realized at a faster speed.

\section{Application}

Example from an urban in Shanxi, the urban altitude is between $1029.00 \sim 1040.00 \mathrm{~m}$. The urban has two water supply sources, one is in the west of the urban, which is coming from reservoirs, the other is a small underground water source in the east of the urban. The model of the urban water distribution network layout shown in Figure 1 which is by EPANET, head loss of pipe is calculated by Hazan-Wiliiams $(H-W)$ formula.

According to the knowledge-based with GA, and the characteristics of water supply source, the urban is divided into two zones-code named I and II , the two regions are separated by valves, namely, valve No.23 on node $5 \sim 6$ pipeline, valve No.25 valves on node $9 \sim 10$ pipeline, valve 
No.26 valve on node 9 14 pipeline, valve No.27 on node 13 14 pipeline.

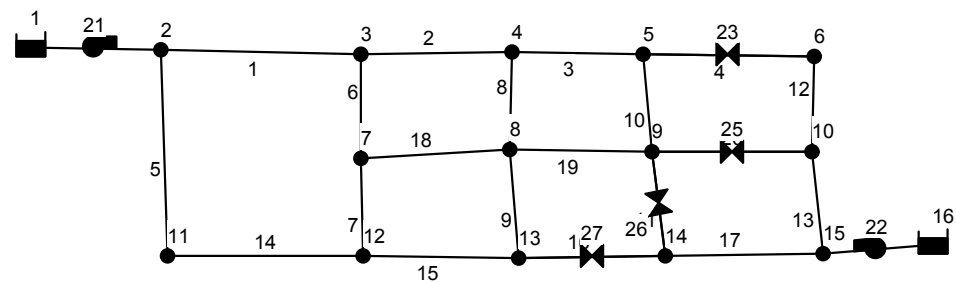

Fig. 1. The model of the urban water distribution network and zones by DMA

When an accident occurs in the II zone, the boundary valves are tried to adjust to ensure that the user's service pressure. When the valve is fully open, attributes of each node and pipeline in the water distribution network is shown in Table 1:

Table1 Flow attributes of pipelines and nodes in this distribution network

\begin{tabular}{ccc|ccc|ccc}
\hline number & Node flow & $\begin{array}{c}\text { Pipeline } \\
\text { flow }\end{array}$ & number & Node flow & $\begin{array}{c}\text { Pipeline } \\
\text { flow }\end{array}$ & number & Node flow & $\begin{array}{c}\text { Pipeline } \\
\text { flow }\end{array}$ \\
\hline 1 & - & 74.26 & 8 & 11.83 & 7.82 & 15 & 4.59 & 26.96 \\
2 & 14.48 & 39.13 & 9 & 14.20 & 2.26 & 16 & - & 22.56 \\
3 & 7.01 & 25.16 & 10 & 8.67 & 6.35 & 17 & - & 9.94 \\
4 & 5.12 & 23.38 & 11 & 6.5 & 6.43 & 18 & - & 31.52 \\
5 & 7.08 & 21.79 & 12 & 13.17 & 6.78 & 19 & - & 25.84 \\
6 & 32.12 & 28.12 & 13 & 6.07 & 5.35 & 20 & - & 11.52 \\
7 & 8.27 & 11.67 & 14 & 7.15 & 52.33 & & & \\
\hline
\end{tabular}

By analysis of the friction coefficient sensitivity equation, the friction coefficient sensitivity coefficient of the various pipeline which valves are adjusted is obtained that are shown in Table 2:

Table 2 The frictional coefficient sensitivity of valves

\begin{tabular}{ccccc}
\hline Valve number & 23 & 25 & 26 & 27 \\
\hline Sensitivity coefficient & 31.65 & 56.42 & 31.10 & 31.91
\end{tabular}

From Table 2, valve No.25 on node 9 10 pipeline, sensitivity coefficient is higher. If the accident occurs on the $10 \sim 15$ pipeline, No.25 valve is first adjusted, and then the other valves. After calculating, when the other valve is closed, valve No.25 is fully open, the service pressure of Zone II changes as Table 3.

Table 3 the pressure change of nodes in this distribution network

\begin{tabular}{cccc|ccc}
\hline number & $\begin{array}{l}\text { Pre-accident } \\
\text { node pressure }\end{array}$ & $\begin{array}{l}\text { Node } \begin{array}{l}\text { pressure } \\
\text { after } \\
\text { adjustment }\end{array} \\
\text { accident }\end{array}$ & number & $\begin{array}{l}\text { Pre-accident } \\
\text { node pressure }\end{array}$ & $\begin{array}{l}\text { Node } \\
\text { after } \\
\text { adjustment }\end{array}$ & $\begin{array}{l}\text { pressure } \\
\text { accident }\end{array}$ \\
\hline 6 & 32.00 & 32.01 & 14 & 32.56 & 31.76 \\
10 & 33.24 & 32.63 & 15 & 34.46 & 33.28 \\
\hline
\end{tabular}

After the accident occurred, node pressure of zone II by valve NO.25 opened is relatively close 
with pre-accident node pressure. Through calculation, it is found that the pressure of each node in the water distribution network is still within the pressure service range of the water supply service enterprise. By the method, the influence on the user service in the II area is relatively small when accident occurred. In this way, the adjusting valve that needs to be opened on the boundary can be found relatively quickly to ensure the service pressure of the users.

\section{Conclusion}

In this paper, main pipelines are tried to be obtained by combining the DMA partitioning and sensitivity. With adjusting the valves which are located on the main pipelines, the partial pressure or the pressure of metered zone can be adjusted to meet the users' service pressure. This method can quickly find the need to adjust the pipeline, thereby enhancing the service pressure in accident and maintenance of water distribution network, and improve service level of water supply enterprises.

The main impact pipelines to the partial pressure have been only studied which is can rapidly locate the position of the valve section. It is need further study that valve adjustment sequence, as well as the regulation of the number of valves in the pipeline and the exact positioning of the valve opening In large-scale water distribution network, this method can be extended to large-scale water distribution network to be explored.as water distribution network can be affected, such as the valve setting and partitioning mode.

\section{Acknowledgements}

This work is financially supported by Natural Science Foundation of Shandong Province (ZR2014EL033).

\section{References}

[1] Di Nardo, A., Di Natale, M., Santonastaso, G. F., and Venticinque, S. 2011 . Graph partitioning for automatic sectorization of a water distribution system. Proc., 11th Int. Conf. on Computing and Controlfor Water Industry (CCWI), Vol. 3, Urban Water Management:Challenges and Opportunities, Centre for Water Systems, Univ. of Exeter, Exeter, U.K., 841 - 846.

[2] Diao, K., Zhou, Y., and Rauch, W. 2013. Automated creation of district metered area boundaries in water distribution systems. J. WaterResour. Plann. Manage., 10.1061/(ASCE)WR.1943-5452.0000247,184 - 190.

[3] Alegre, H., Coelho, S. T., Martins, A., \& Mamade, A. 2014. A new approach to improve water loss control using smart metering data. Water Science \& Technology Water Supply, 14(4), 618-625.

[4] Nicolini, M., \& Zovatto, L. 2009. Optimal location and control of pressure reducing valves in water networks. Journal of Water Resources Planning \& Management, 135(3), 308-310.

[5] Ali, Mohammed E. "Knowledge-Based Optimization Model for Control Valve Locations in Water Distribution Networks." Journal of Water Resources Planning \& Management 141.1(2014):04014048.

[6] Cui Jian-guo, YU Qing-jiang, LIANG Hai-rong. 2004. Study On the Method Dividing Districts of Water Distribution Network in Optimal Dispatch of City Water Supply System. Journal of Taiyuan University of Technology, 35(5):605 608

[7] Wang Shu-gang, Jiang Shuang, Wang zong-shan. 2006. Sensitivity of steady fluid piping networks , Journal of Dalian University of Technology, 46(5):720 724

[8] Palleti, V. R., Narasimhan, S., \& Rengaswamy, R. (2014). Optimal sensor placement for 
contamination detection and identification in water distribution networks. Computer Aided Chemical Engineering, 33(1), 1447-1452.

[9] Araujo, L. S., Ramos, H., \& Coelho, S. T. 2006 . Pressure control for leakage minimisation in water distribution systems management. Water Resources Management, 20(1), 133-149.

[10]Xin Kun-long, Zhan Shu-jun, Tao tao ,etc. 2014. Multi-objective calibration of hydraulic model in water distribution network based on sensitivity analysis, Journal of Tongji University, 42(5):736 739 